\title{
Editorial: Hacia una cultura de indexación de las revistas científicas
}

\author{
Cristian, Rivas-Castillo ${ }^{1}$ \\ (iD https://orcid.org/0000-0001-6827-1462 \\ Universidad Politécnica de Nicaragua UPOLI
}

En la actualidad la información ya no se considera como algo inerte o estático, sino, como algo dinámico, debido a que es producida por el pensamiento humano, en este sentido, la información debe ser un patrimonio de la sociedad, es así, como la UNESCO constantemente realiza foros internacionales para fomentar la creación de políticas públicas nacionales e internacionales en información científica.

Por consiguiente, esta necesidad de llevar la información a la sociedad ha llevado al hombre a crear herramientas, que permitan encontrar, utilizar, almacenar y estudiar la información. Dentro la gran variedad de información que se puede encontrar en la web, se encuentra la información científica, sin embargo, hay que comprender que la ciencia al ser un constructo social tiene sus propios canales de "comunicación, ritos, valores, normas, reglas y principios éticos" (López y Cordero, 2005. p. 57) a este proceso se le denomina publicaciones científicas y son la base para la transferencia y difusión del conocimiento científico.

Es así, como surgieron en los años setenta los sistemas de información, el primer país en desarrollarlos fue Estados Unidos con la aparición del Medline en el área de las ciencias médicas, posteriormente, se comenzaron a desarrollar otros sistemas de información en varias partes del mundo, como el EUDISED en Europa, en España se desarrolló con el financiamiento de la UNESCO el boletín internacional de bibliográfica y en América Latina se desarrolló el REDUC, el cual fue un esfuerzo por integrar el conocimiento de toda la región.

Por esta razón, a este proceso de inclusión de las publicaciones científicas en sistemas de información se le denomina indexación o indización, Padula (2019) conceptualiza a la indexación como "un listado, que generalmente indica una ubicación en atención a distintos criterios de calidad y facilita su consulta" (p. 25). En este sentido, que una publicación o revista científica se encuentre indexada significa que la misma denota calidad y ha sido encasillada en alguna base de datos de consulta sean estas nacionales, regionales o mundiales.

En este sentido, la indexación de las revistas o publicaciones científicas en índices, repositorios o bases de datos de alto impacto es vital para la reputación y alcances de los documentos publicados en estas, sin embargo, para la inclusión de las revistas en algunos de estos sistemas es necesario que se cumplan con ciertos criterios de calidad, los cuales estarán sujetos al tipo de sitio que se pretenda indexar.

\footnotetext{
${ }^{1}$ Maestrante en Relaciones Internacionales por la Universidad Autónoma de Nuevo León, México. Licenciado en Derecho por la Universidad Nacional Autónoma de Nicaragua. Ex becario CONACYT, México. Coeditor de la Revista Ciencia Jurídica y Politica. Investigador en temas de políticas públicas, participación ciudadana y derecho internacional. Correo Electrónico: Castillocris25@yahoo.com. https://portalderevistas.upoli.edu.ni/index.php/5-revciencasjuridicasypoliticas/article/view/639
} 
Ahora bien, dentro de los criterios generales que evalúan los sistemas de información se encuentran la calidad informativa, las características formales, el uso que se le da a la información y calidad científica de los contenidos, en el primer criterio mencionado se examina que las revistas cuenten con un cuerpo editorial el cual debe ser identificable en su plataforma, así como, establecer de forma clara las orientaciones para los autores, el proceso de evaluación, traducción de los resúmenes en otro idioma distinto al de origen y el uso de palabras claves, en el segundo criterio es necesario que las revistas cumplan con la periodicidad que se han impuesto, también, que realizan revisión por pares, contar con un comité científico externo y utilizar los canales adecuados para dar a conocer las decisiones editoriales, en el tercer criterio se evalúa que los autores que realizan publicaciones sean externos a la entidad editora, así como, un alto contenido científico.

Posteriormente, una vez que los editores evalúen si cumplen con los requisitos generales para indexar sus publicaciones es el momento de seleccionar la base de datos que mejor se adapte a la temática del diario, sin embargo, es necesario conocer que existe una clasificación de estos sistemas de información, que van de lo básico como los catálogos de bibliotecas hasta lo complejo como las bases de datos alto impacto (Scopus, Scimago Journal y Web of Science).

En este sentido, se recomienda realizar el proceso de indexación por etapas, la primera es incluir la revista en Catálogos de bibliotecas (CCUC, UOC, WorldCat), Directorios de publicaciones periódicas (Dialnet, DOAJ, Sherpa/Romeo, Dulcinea, REDALYC, DRJI, REDIB) y Redes sociales académicas (Google Scholar, Mendeley, Research Gate, Publoms), en la segunda etapa se debe de indexar la revista en base de datos del área temática de esta, en la tercera etapa se recomienda incluir la revista en índices de prestigio que permitan evaluar y medir el impacto del diario (MIAR, CIRC, ERIH+, Latindex), y por último se recomienda incluir la revista en las bases de alto impacto (Scopus, Web of Science, Journal Citation Report, Scimago Journal Rank).

Ciertamente, la inclusión de las revistas científicas en cualquiera de las bases de datos antes mencionada, permitirá en primer lugar evaluar el trabajo realizado por el cuerpo editorial, asimismo, permitirá evaluar si las revistas cumplen con los estándares internacionales y aumentar la visibilidad e impacto del diario, por otro lado, hará posible que autores internacionales y de renombre publiquen sus investigaciones en la revista.

Por lo anteriormente mencionado, es necesario que toda organización que se dedica a la publicación periódica de revistas priorice la indexación, para aumentar el alcance y visibilidad del trabajo realizado, en este sentido, la Escuela de Ciencias Jurídicas y Políticas comprometida con la difusión y calidad de la información científica ha implementado en los últimos meses un proyecto de indexación de sus revistas científicas, con el objetivo de satisfacer las necesidades de los investigadores y comunidad científica internacional.

En este aspecto, desde el año 2018 la Revista Ciencia Jurídica y Politica a través de su equipo editorial ha venido realizando esfuerzos por lograr la indexación del diario en repositorios, bibliotecas, directorios, índices y sistemas de evaluación, obteniendo como resultado el reconocimiento de la revista en 18 bases de datos a nivel internacional entre la que destacan 
(Erihplus, Copernicux Índex, Miar, Journal Factor Impact, Base, LatinRev, Eurasian Scientific Journal Índex, Europub, Entre Otras).

La inclusión de la Revista Ciencia Jurídica y Política en estas bases de datos ratifica el compromiso de la Escuela de Ciencias Jurídicas y Políticas de la Universidad Politécnica de Nicaragua de difundir información científica de calidad en temas relacionados al Derecho y la Politica. En este nuevo número se presentan artículos de autores de México, España y Nicaragua con temáticas novedosas y de interés para la comunidad académica.

En primer lugar, el Doctor Gorjón-Gómez y la Maestra Valdés-Espinosa abordan un tema innovador y de trascendencia para la disciplina de los Métodos Alternos de Solución de Conflictos, a como lo es la "Creatividad" en la mediación, lo cual permitirá abordar los conflictos de una manera distinta y, por lo tanto, se logrará llegar a soluciones novedosas y ágiles. Siguiendo esta misma línea, el Maestro Sequeira Pérez nos presenta un artículo en el cual se realiza un análisis jurídico integral sobre el principio de separabilidad de la cláusula arbitral en la interpretación y modificación de los contratos, el autor establece la importancia de este principio del derecho en la búsqueda de soluciones a problemas contractuales.

Por otro lado, el doctorando Palomino-Flórez desarrollo una investigación en el área del derecho tributario en la cual se estudió de manera comparativa el deber de contribuir y el derecho de no autoincriminación en relación con los deberes que tiene el individuo frente a la hacienda pública en la legislación española. Asimismo, se presenta el articulo elaborado por la Maestra Manzanares Garmendia en el cual se aborda un tema de importancia tanto para la sociedad en general a como lo es el "Desarrollo Sostenible", el autor realiza un análisis de la complejidad de crear políticas públicas que incorporen de manera holística los enfoques existentes en materia de Desarrollo Sostenible.

Por último, se presenta en este número un estudio en el cual se analiza la figura jurídica del "Amparo Local" en la constitución política del Estado de Guanajuato, México. Esta investigación es realizada por el Doctor Olguin Torres, y resalta la importancia que tiene para los sistemas democráticos el reconocimiento de mecanismos que favorezcan a la protección efectiva de los derechos vulnerados.

La Revista Ciencia Jurídica y Politica agradece a todos los que han hecho posible la realización de este número, especialmente a las autoridades de la Escuela de Ciencias Jurídicas y Políticas y la Universidad Politécnica de Nicaragua.

\section{Referencias.}

Padula, Danielle. (2019). Indexación de revistas: estándares básicos y por qué son importantes. LSE Impact of Social Sciences.

López, O., \& Cordero, A. (2005). Un intento por definir las características generales de las revistas académicas electrónicas. Razón y palabra. 